\title{
Position paper \\ THE MEANINGFUL SILENCES OF THE WASTE INCINERATION BREF BAT-CONCLUSIONS
}

\author{
Hubert de Chefdebien * \\ CNIM Environment, 35 rue de Bassano, 75008, Paris, France
}

All installations included in the scope of the Industrial Emission Directive (IED, Directive 2010/75/EU), must prevent and reduce pollution, use energy efficiently, prevent accidents and limit their consequences by applying the Best Available Techniques (BATs). In order to define at European Union level BATs and the BAT-Associated Environmental Performance (BATAEPLs), the Commission organises an exchange of information with experts under the coordination of the European IPPC Bureau (EIPPCB, European Integrated Pollution Prevention and Control Bureau). The experts, nominated by Member States, Industry and Environmental organisations are organised in Technical Working Groups (TWGs), one for each industrial sector covered by the IED. This process results in Bat REFerence documents (BREFs). The chapter containing the so-called BAT conclusions of each BREF is designed as a standalone document. After Member States approval, the BAT conclusions, adopted by the Commission, are published in the Official Journal of the European Union as a Commission Implementing Decision, which is directly applicable without transposition. Within 4 years of publication of a Decision on BAT conclusions, the environmental permits of all interested installations must be adapted to the new requirements and, if necessary, retrofitting work undertaken to ensure that BATs are implemented and, in particular, that Emission Limit Values (ELVs) are set to ensure that emissions do not exceed BAT Associated Emission Levels (BATAELs). The BAT conclusions on Waste Incineration (WI), are currently in the finalisation process and should be published during summer 2019.

At first glance, the BAT-conclusions seem quite straightforward. However, when the time for implementation comes it will be clear that there is a lack of background information on how to understand them, how to apply them and on the applicability of the BATAELs ranges. In fact, BAT-conclusions frequently fail to provide reference to other complementary legal requirements, and to useful contextual information shared during the exchange within the WI BREF TWG.

The purpose of this paper is to advise stakeholders against a hasty use of the BAT-conclusions. There are a number of causes for concern in the Waste Incineration BAT conclusions. Very little information was collected by the EIPPCB on cross-effects and costs. BATAELs are based on data provided by operators of well performing plants in answer to a questionnaire. Most of the BATAEL ranges were defined by selecting some of the reported emissions (usually amongst the lowest) and substance by substance, independently from each other. In the BAT conclusions, BATAELs are expressed as frequently wide ranges. Very little information is provided on how to understand and use these ranges. It is important to note that none of the plants used to set the BATs/BATAEPLs fat the same time achieved the maximum performances of the BAT conclusions: lower end of all BATAELs as well the upper end of BAT Associated Energy Efficiency Levels (BATAEELs). Moreover, BATAELs are directly derived from operating values. BATAEL-based ELVs should be set considering a margin for operating contingencies and uncertainty.

\section{NOC/OTNOC/EOT}

The IED defines BATAELs (see IED Article 3 - 13) and requires that ELVs be set by competent authorities to ensure that emissions do not exceed BATAELs. However, the IED does not mention BATAEPLs (BAT Associated Environmental Performance Levels) that were introduced by the Guidance for the drawing up of BREFs (Commission Implementing Decision of 10 February 2012) which does not require them to be applied. Nevertheless the WI BREF BAT conclusions do not say that the BATAEPLs it contains (BATAEELs, BAT Associated Energy Efficiency Levels) are not imposed by IED as BATAELs are.

For future requirements regarding incineration ELVs, the legal picture will become twofold: a set of new BATAEL-based ELVs in NOC (Normal Operating Conditions) plus the existing ELVs in EOT (Effective Operating Time), for some continuously monitored substances.

Indeed, on the one hand, there will be BAT Conclusions and their BATAELs. In accordance with the IED (Art. 3.13 and 15.3), BATAELs are defined under NOC (IED Art. 3.13) and future ELVs, that must be set to ensure that emissions do not exceed BATAELs, should as well be established under NOC. (IED Art. 15.3) This will apply to daily average values of continuously monitored substances and to periodically monitored substances. 
On the other hand, the incineration sector is the only industrial sector for which compliance with the current ELVs (the ones laid down in IED Annex VI) of the continuously measured emissions is required within the EOT, i.e. as soon as and as long as waste is burning (see IED Annex VI, Part 8, §1.2). Therefore, the IED Annex VI ELVs will still apply in EOT (= NOC + OTNOC, Other Than Normal Operating Conditions) for daily averages and for $1 / 2-h r$ averages. See the summary of this dual requirement in Table 1.

Some points need clarification. The BAT conclusions do not remind the reader that BATAELs are defined in NOC. The IED does not define NOCs. There are some examples of OTNOC situations in the IED (Articles 14.1.f and 47) and in the BREF Guidelines (Decision 2012/119/EU, in $\S$ 4.6.2.2.3.ii § 5.4.7.2.6). For instance, OTNOC include startup and shut-down operations, leaks, malfunctions, breakdown, regular maintenance, exceptional conditions. See an example on Figure 1. The EIPPCB said that the calculation and compliance conditions for BATAEL-based ELVs in NOC are not necessarily the same as the ones of IED Annex VI for EOT ELVs but did not defined those.

\section{Uncertainties}

The IED defines BATAELs (see IED Article 3 (13)) and requires that ELVs be set by competent authorities to ensure that emissions do not exceed BATAELs. However, the IED does not mention BATAEPLs (BAT Associated Environmental Performance Levels), introduced for the drawing up of BREFs (Commission Implementing Decision of 10 February 2012), for which their application is not compulsory. Nevertheless, the WI BREF BAT conclusions fail to state that the BATAEPLs contained (BATAEELs, BAT Associated Energy Efficiency Levels) are not imposed by IED in the same way as BATAELs.

For future requirements regarding incineration ELVs, the legal picture will become twofold: a set of new BATAEL-based ELVs in NOC (Normal Operating Conditions) plus the existing ELVs in EOT (Effective Operating Time), for some continuously monitored substances.

Indeed, on the one hand, there will be BAT Conclusions and their BATAELs. In accordance with the IED (Art. 3.13 and 15.3), BATAELs are defined under NOC (IED Art. 3.13) and future ELVs, that must be set to ensure that emissions do not exceed BATAELs, should also be established under NOC. (IED Art. 15.3) This will apply to daily average values of continuously monitored substances and to periodically monitored substances.

On the other hand, the incineration sector is the only industrial sector for which compliance with the current ELVs (those laid down in IED Annex $\mathrm{VI}$ ) of the continuously measured emissions is required within the EOT, i.e. as soon as

TABLE 1: Regulatory requirements on compliance either in NOC or within the EOT for the different air ELVs.

\begin{tabular}{|c|c|c|c|c|}
\hline Monitoring regime & Period & Substances & BATAEL-based ELVs & IED Annex VI ELVs \\
\hline \multirow{4}{*}{ Continuous } & \multirow[t]{2}{*}{ Daily average } & $\begin{array}{c}\text { Dust, } \mathrm{HCl}, \mathrm{HF}, \mathrm{SO}_{2}, \mathrm{NOx} \\
\mathrm{TOC}, \mathrm{CO}\end{array}$ & In NOC & $\begin{array}{c}\text { In EOT (NOC \& OTNOC } \\
\text { when waste burning) }\end{array}$ \\
\hline & & $\mathrm{Hg}, \mathrm{NH}_{3}$ & In NOC & - \\
\hline & $1 / 2$-hr average & $\begin{array}{c}\text { Dust, } \mathrm{HCl}, \mathrm{HF}, \mathrm{SO}_{2}, \mathrm{NOx} \text {, } \\
\text { TOC, } \mathrm{CO}\end{array}$ & - & \multirow{2}{*}{$\begin{array}{c}\text { In EOT (NOC \& OTNOC } \\
\text { when waste burning) }\end{array}$} \\
\hline & 10-min average & $\mathrm{CO}$ & - & \\
\hline Periodic & Every 6 months & Heavy metals, PCDD/F & In NOC & in NOC \\
\hline Continuous sampling & $\begin{array}{l}2 \text { to } 4 \text { weeks } \\
\text { every month }\end{array}$ & PCDD/F \& PCB-DL & In NOC & - \\
\hline
\end{tabular}

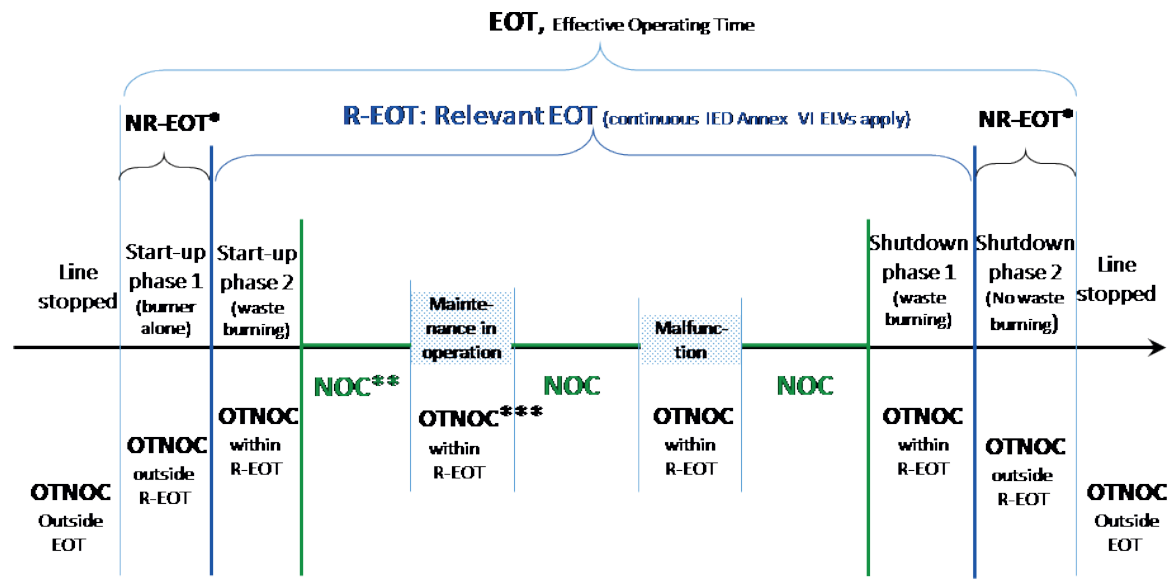

* NR-EOT: Non relevant EOT (contimsons IED Armex VI EIVs do not apply)

** NOC: Normal Operating Conditions (BATAEL based Elvs apply)

*** OTNOC: Other Than Normal Operating Conditions (BATAEL based Elvs do not apply)

FIGURE 1: Successive OTNOC and NOC situations within the EOT (chronologically). 
and as long as waste is burning (see IED Annex VI, Part 8, §1.2). Therefore, the IED Annex VI ELVs will still apply in EOT (= NOC + OTNOC, Other Than Normal Operating Conditions) for daily averages and for $1 / 2$-hr averages.

Some points should be further clarified. The BAT conclusions do not inform the reader that BATAELs are defined in NOC, and the IED does not define NOCs. A few examples of OTNOC situations are cited in the IED (Articles 14.1.f and 47) and in the BREF Guidelines (Decision 2012/119/ EU, in § 4.6.2.2.3.ii § 5.4.7.2.6). For instance, OTNOC refers to start-up and shut-down operations, leaks, malfunctions, breakdown, regular maintenance, exceptional conditions. The EIPPCB have stated that calculations and compliance conditions for BATAEL-based ELVs in NOC are not necessarily the same as those envisaged in IED Annex VI for EOT ELVs, whilst however failing to define the latter.

The main concern is most probably the uncertainty issue. The EIPPCB authors checked the LoQ (Limit of Quantification) for online instruments but did not take into account the overall uncertainty of measurements and, in particular, the significant part resulting from online calibration of instruments by control bodies, from the sampling system and of the Data Acquisition and Handling System. BATAELs are therefore expressed without information relating to uncertainty. The EIPPCB stated that the implementation of BATAELs to set ELVs and compliance monitoring is the Member States' responsibility, thus allowing requirements on uncertainty during the BREF review to be wholly disregarded.

A study conducted by INERIS, the French official Institute expert on monitoring, on request of the professional associations CEWEP, ESWET and FEAD within the context of the WI-BREF revision was shared with the Technical Working Group, including the EIPPCB. The study showed how the performances of the monitoring techniques available on the market, mainly Standard Reference Methods (SRM), do not meet the requirements of the monitoring standards made compulsory by the IED in respect of the maximum levels of uncertainty:

- Already, for the majority of controlled substances, at the level of IED Annex VI ELVs.

- A fortiori for the BATAEL ranges proposed in Waste Incineration BREF draft, all of which are equal to or below IED's ELVs.

The incineration sector emissions are currently the lowest of all combustion industries. If ELVs are lowered, the relative uncertainty will significantly increase, making compliance with standard requirements in respect of maximum acceptable uncertainty even more impossible to achieve. No significant improvement is foreseen in the coming years to address this problem.

The situation can be tolerated for ELVs equalling or close to the IED Annex VI ELVs since operating values are, in practice, significantly lower than ELVs. The margin between the two compensates for the fact that uncertainty is greater than required by the standards. However, for most pollutants, if ELVs are set below the BATAEL upper ends, there will be no margin, or it will be insufficient to compensate, should uncertainties be higher than required. See Figure 2 .

The extreme difficulty to perform meaningful QAL2 (Quality Assurance level 2) calibration tests (defined by EN 14181 standards) when concentrations are very low and stable is well known (see Figure 3 ). It will be virtually impossible to properly calibrate the instruments in such cases with lower ELVs. The use of calibration gas will not help since this should be performed close to daily ELV levels, which is often already impossible at some Annex VI ELVs levels (see Figure 4). Calibration gases at very low concentrations with good accuracy are not available. Dilution introduces uncertainties. Reference material are not available for some pollutants such as dust. Artificially high concentration in one pollutant (the span gas) will mask the
Current situation:

- Very low emissions

- There is a margin to the $B V$

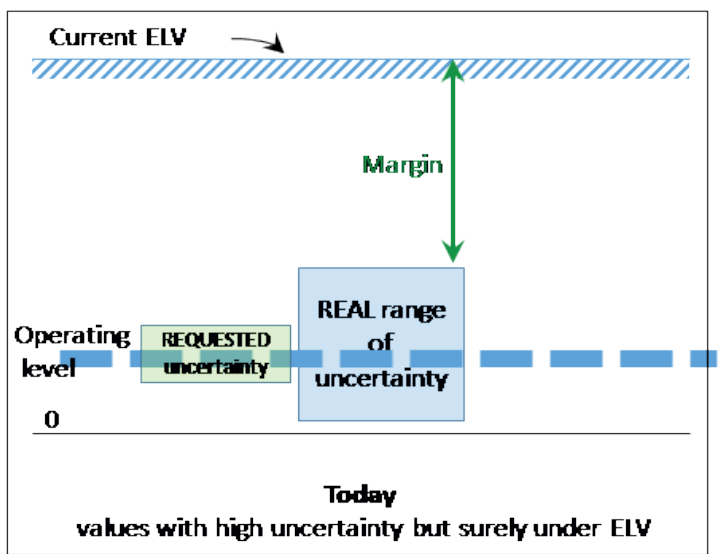

Future situation:
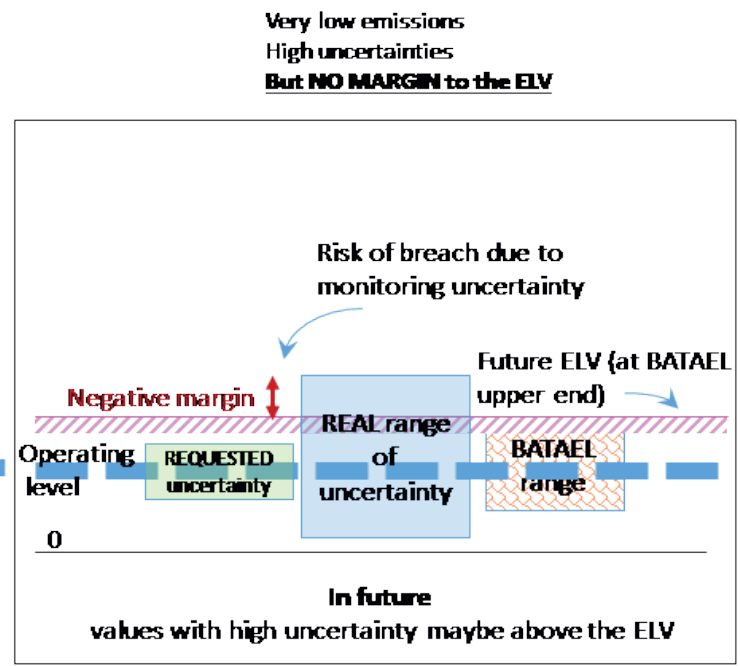

FIGURE 2: The actual uncertainty is significantly higher than the uncertainty required by the standards at ELV level. As the concentrations obtained today are much lower than the ELV, and thanks to the margin between operating value and ELV, the operator and the regulator are certain that the values - although not exact - are below the ELV (as shown on the left). If the ELV is lowered in the future at lower BATAEL levels, because of the actual uncertainty, it will be impossible to ascertain whether the emissions are actually below the ELV (as shown on the right). 


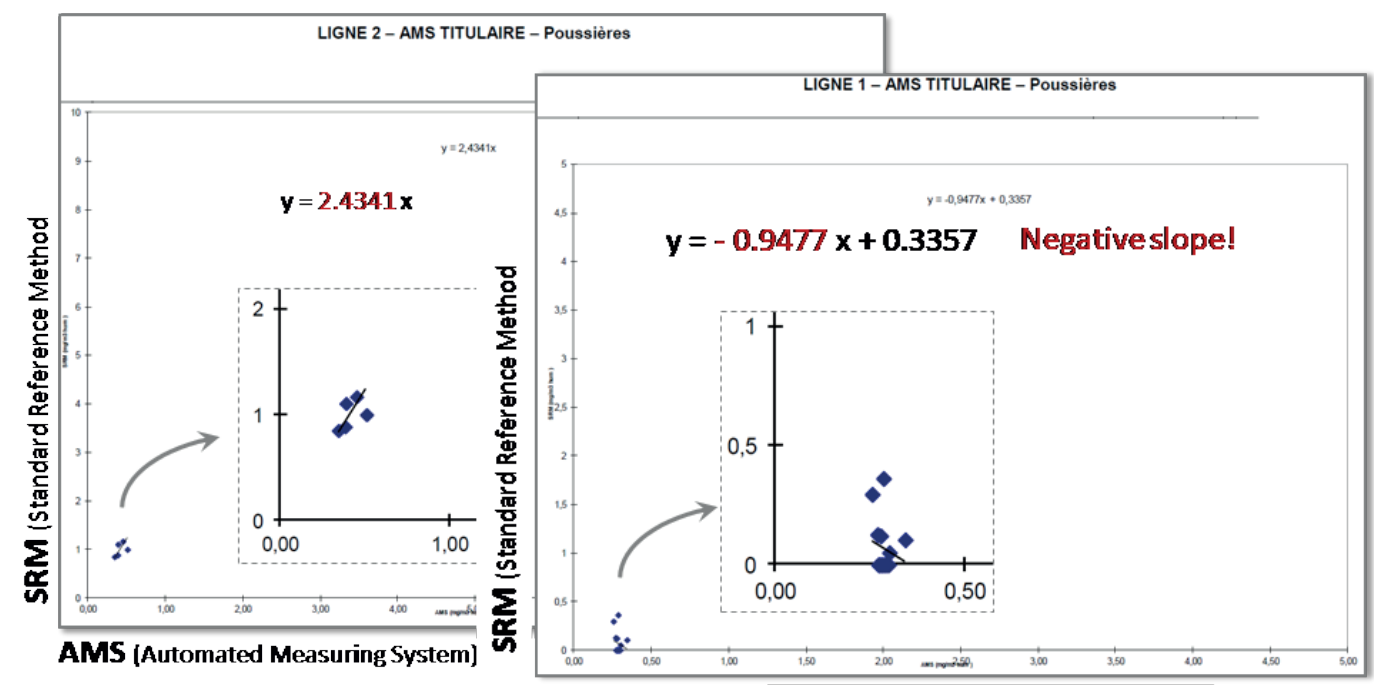

AMS (Automated Measuring System)

FIGURE 3: Example of correction curve for on-site calibration (QAL2) obtained for dust on two lines of a Waste-to-Energy plant. Online instrument (AMS) on the X-axis. Standard Reference Method (SRM) on the Y-axis. As can be seen on both graphs, AMS and SRM readings are very similar. However, since the concentrations are very low and constant, the calibration functions calculated in accordance with the standards yield irrelevant results: $y=2.4341 \mathrm{x}$ in one case and $\mathrm{y}=-0.9477 \mathrm{x}+0.3357$ in the other. In principle, the AMS readings are corrected according to SRM readings, which are supposedly correct. Here, the points are very close to each other and at very low concentrations. This does not allow for any statistically reliable conclusion to be drawn. On the right, the obtained straight line maintains a negative slope, meaning that, if it were to be used, the higher the value read by the online instrument, the lower the corrected value. As always with low and constant concentrations, both QAL2 tests passed the validating variability test, thus demonstrating the need for revision of the EN 14181 standards.
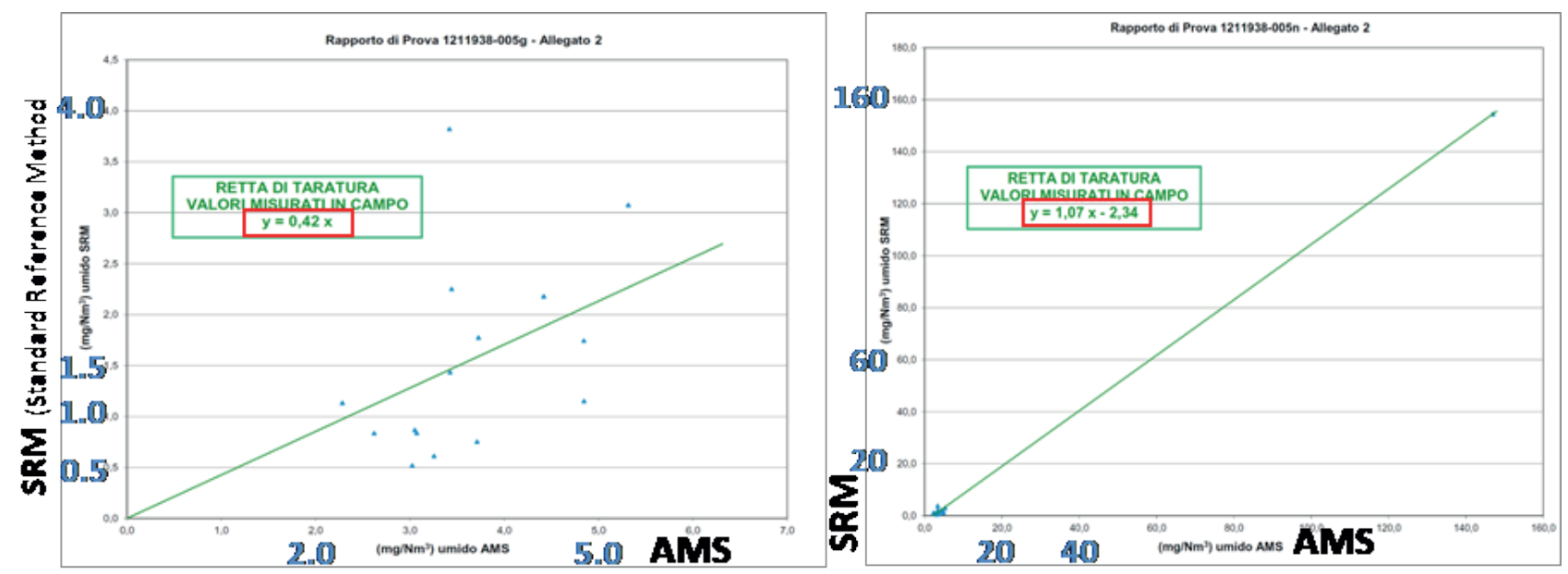

FIGURE 4: QAL2 calibration on $\mathrm{SO}_{2}$ with and without span gas on the same Waste-to-Energy line on the same day. On the left without spike gas. If the reported value is $1.5 \mathrm{mg} / \mathrm{Nm}^{3}$ (on the green line), the corresponding readings of the AMS are in a range of 2.2 to 4.9 and those of the SRM in a range of 0.6 to $3.8 . \mathrm{mg} / \mathrm{Nm}^{3}$. On the right with spike (calibration) gas at $160 \mathrm{mg} / \mathrm{Nm}^{3}$, which is high since the standards dictate that the concentration should not differ markedly from the daily ELV, which is $50 \mathrm{mg} / \mathrm{Nm}^{3}$ for $\mathrm{SO}_{2}$. The calibration function is better $(y=1.07 x-2.34$, instead of $y=0.42 x)$ but when looking at the cluster of dots on the bottom left (the same dots seen in the first graph), the benefit of spiking to improve accuracy at low concentrations appears dubious.

interferences occurring between the different substances in the actual flue gas.

To be on the safe side, it may be appropriate to set ELVs at all BATAELs lower ends and BATAEPL higher end. However, as seen above, some crucial information should be taken into account when implementing WI BREF BAT conclusions. Setting ELVs based on BATAEL values below the upper ends of the ranges requires extreme caution. In fact, the challenge is not to establish abatement techniques, which can meet very low emissions, but rather to provide evidence that the measurements comply with the requirements of monitoring standards with regard to uncertainty.

For decades, the waste incineration sector has been the industry sector featuring the lowest emission levels and has minimized the effect on the environment and public health. It is important that these low gains be placed in perspective in relation to the higher gains which could be obtained more economically when dealing with sources of pollution other 
than the Waste-to-Energy sector in the same local context.

CEWEP, ESWET and FEAD are currently finalising an explanatory guidance document to provide background information aimed at identifying the concerns raised by the $\mathrm{W}$ BREF BAT conclusions and to propose potential solutions. Pre-final draft is expected in June 2019.

\section{ABBREVIATIONS}

\section{Reference Documents}

- IED: Industrial Emission Directive (2010/75/EU) of 24/11/2010

- WI BREF: Waste Incineration BREF

\section{Best Available Techniques}

BAT: Best Available Techniques

BREF: BAT REFerence document

- BATAELs: Best Available Techniques Associated Emission Levels

- BATAEELs: Best Available Techniques Associated Energy Efficiency Levels

- BATAEPLs: Best Available Techniques Associated Environmental Performance Levels

\section{Stakeholders}

EIPPCB: European IPPC Bureau

- TWG: Technical Working Group

- CEWEP: The Confederation of European Waste-to-Energy Plants (Operators)

- ESWET: European Suppliers of Waste to Energy Technology

- FEAD: Fédération Européenne des Activités du Déchet

\section{Operating Conditions}

- NOC: Normal Operation Conditions

- OTNOC: Other Than Normal Operation Conditions

EOT: Effective Operating Time

- R-EOT: Relevant EOT

- NR-EOT: Non-Relevant EOT. (Period of EOT when no waste is burning, i.e. when only the burner(s) is/are in operation)

\section{Emissions}

- ELVs: Emission Limit Values. (Sets of ELVs are given in IED Annex VI. IED Article 15.3 requires to also set BATAEL-based ELVs)

- PCDD, PCDF or PCDD/F: Polychlorodibenzo-dioxins \& furans

- PCB-DL: PCB-Dioxin Like. 12 PCBs are "dioxin-like"

\section{Monitoring}

- AMS: Automated Measuring System

- SRM; Standard Reference Method

- LoQ: Limit of Quantification

- QAL2: Quality Assurance Level 2

\section{REFERENCES}

INERIS (2017). Study of the performances of existing and under development AMSs (Automated Measuring Systems) and SRMs (Standard Reference Methods) for air emissions at the level of and below existing ELVs (Emission Limit Values) and BATAELs (Best Available Techniques Associated Emission Levels) for Waste Incineration, Co-incineration and Large Combustion Plants. Study report 10/11/2017 N DRC-17-168319-02463B. https://www.ineris. $\mathrm{fr} / \mathrm{fr} /$ study-performances-existing-and-under-development-amssautomated-measuring-systems-and-srms-0, accessed the 18th of March 2019.

Waste incineration Final draft is availale with other BREFs at: http:// eippcb.jrc.ec.europa.eu/reference/ 